\title{
Ortaokul Öğretmenlerinin Ara Tatil Hakkındaki Görüşleri: Bir Karma Yöntem Çalışması
}

\section{Suat KAYA*}

Öz: Bu çalışmanın amacı ortaokul öğretmenlerinin ara tatil uygulaması hakkındaki görüşlerini incelemektir. Çalışma için nitel ve nicel verilerin aynı anda toplanmasını mümkün kılan karma araştırma modellerinden eşzamanlı gömülü strateji araştırma deseni olarak kullanılmıştır. Küme örnekleme yöntemiyle seçilen 281 öğretmen çalışmanın örneklemini oluşturmaktadır. Araştırmacı tarafından geliştirilen ve 25 madde ile alt soruları olan açık uçlu bir sorudan oluşan bir anket veri toplama aracı olarak kullanılmıştır. Nicel veriler ortalama, frekans ve yüzdeliklerle analiz edilirken, açık uçlu sorudan elde edilen veriler içerik analizi ile analiz edilmiştir. Araştırma bulguları, öğretmenlerin ara tatilde verilen mesleki çalışma programından genel olarak memnun olduklarını göstermiş ve ara tatilin birçok olumlu yönüne 1şsk tutmuştur. Gelecekteki programlara öğretmenlerin ihtiyaç duydukları eğitimlerin de eklenerek bu dönemdeki programın devam ettirilmesi önerilmiştir.

Anahtar Kelimeler: Öğretmen eğitimi, ara tatil, mesleki eğitim programı

\section{Middle School Teachers’ Views About Mid-term Break: A Mixed Method Study}

Abstract: The purpose of this study was to examine middle school teachers' views about the mid-term break. Concurrent embedded strategy, one of the mixed methods models that enable collection of both quantitative and qualitative data simultaneously, was used as the research design for this study. The sample consisted of 281 teachers selected through a cluster sampling method. A questionnaire, which was developed by the researcher and included 25 items and an open-ended question including probing questions, was used as data collection instrument. The

*Dr. Öğretim Üyesi, Ağrı İbrahim Çeçen Üniversitesi, Sivil Havacılık MYO, Email:sukaya@agri.edu.tr , Orcid No: 00000001-6593-3205.

${ }^{* *} \mathrm{Bu}$ araştırma için Ağrı İbrahim Çeçen Üniversitesi, Bilimsel Araştırmalar Etik Kurulu Başkanlığı'ndan (08/09/2020 tarih ve 115 sayısı) etik izin alınmıştır. 
quantitative data were analyzed with mean, frequency and percentages, while content analysis was applied to the qualitative data obtained from the open-ended question. The findings revealed that in addition to many positive aspects of the mid-term break, teachers were generally satisfied with the professional training program implemented during this break. This program was recommended to be continued and the trainings that teachers needed were suggested to be included in future training programs.

Keywords: Teacher education, mid-term break, professional training program

\section{Giriş}

Toplumların gelişerek ilerleyebilmesinde eğitimin, özellikle okullarda verilen eğitim ve öğretimin rolü yadsınamaz. Ancak okullarda iyi bir eğitimin verilebilmesi okuldaki öğretimin niteliğinin yükseltilmesine bağlıdır (Seferoğlu, 2004). Bu bağlamda, eğitim olgusunun üç temel öğesinden biri olan öğretmenler (Üstüner, 2004), eğitimin en etkin insan unsurunu oluşturmaktadır (Celep, 2008; Kayabaş, 2008). Toplumun geleceğini şekillendirecek öğretmenlerin kaliteli bir eğitim verebilmesi için de iyi bir eğitim alması ve kendilerini sürekli olarak geliştirerek değişen çağa ve koşullara ayak uydurmaları beklenmektedir. Bu durum öğretmen yetiştirme sürecinin sürekli bir hal almasını gerektirmektedir.

Öğretmen yetiştirme, kısaca öğretmen adaylarının belirli bir süre içinde öğretmenlik mesleğine hazırlanması amacıyla yapılan etkinliklerden oluşur (Aykaç, Kabaran ve Bilgin, 2014). Türkiye’de bu süreç “ [1] yetiştirilecek adayların seçimi, [2] belirli bir süre ve program dâhilinde eğitimleri (hizmet öncesi eğitim), [3] görevlendirilecek olan öğretmen adaylarının seçimi (kamu personeli olarak atanma) ve [4] görev başındaki öğretmenlerin eğitimleri (hizmet içi eğitim) aşamalarından oluşmaktadır” (Akdemir, 2013, s. 16). Bu eğitimlere lisansüstü eğitim de ayrıca eklenebilir (Güneş, 2016), çünkü lisansüstü eğitimler de mesleki gelişime katk1 sağlayacak önemli bir eğitim sürecidir.

Öğretmenlerin, meslek yaşamları boyunca gerekli bilgi ve becerileri edinmeleri ve kendilerini geliştirmeleri hizmet içi eğitim programları yoluyla karşılanmaktadır (Gültekin, Güvey-Aktay ve Gültekin, 2018). Bu bağlamda, mesleki gelişim yaşam boyu öğrenmenin bir yansıması olarak kabul edilebilir (Elçiçek, 2016), çünkü “yaşam boyu eğitim, mevcut sistemi yeniden yapılandırmayı ve formal eğitim sisteminin dışında eğitimle ilgili tüm potansiyeli 
geliştirmeyi amaçlayan genel bir düzenlemedir ve örgün, yaygın her türlü eğitim faaliyetini kapsayan geniş bir kavramdır" (Güleç, Çelik ve Demirhan, 2012, s. 35).

Bilindiği üzere, 2018-2019 eğitim-öğretim yılına kadar Türkiye'de eğitim-öğretim yılı başında ve eğitim-öğretim yılı sonundan Temmuz ayının ilk iş gününe kadar öğretmenlere seminer adı altında verilen mesleki çalışma programları verilmekteydi. Fakat, alanyazında bu konuda yapılan çalışmalar incelendiğinde bu eğitimlerin çok da sağlıklı geçmediğini gösteren birçok bulguya rastlamak mümkündür. Araştırma bulguları, öğretmenlerin, mesleki gelişim seminer çalışmalarını bir formalite olarak gördüğü (Ceylan ve Özdemir, 2016; Tonbul, 2004) ve çalışma rapor sonuçlarından yararlanılmadığ (Tonbul, 2004); bu çalışmaların uzman ve yetkin olmayan kişiler tarafindan yürütüldüğü (Boydak-Özan, Şener ve Polat, 2014; Gümüş, 2006; Öztürk ve Sancak, 2007); bu çalışmaların gerekli ve faydalı olduğu fakat bu çalışmalara ayrılan sürenin yetersiz olduğu (Gültekin ve Çubukçu, 2008; Gümüş, 2006); çalışmalara ayrılan sürenin nitelikli olmadığı (Gümüş, 2006); farklı bölge ve okullarda çalışan öğretmenlerin mesleki gelişim ihtiyaçları arasında farklılıklar olduğu (Akar, 2006) ve amacına uygun yapılmadığını (Boydak-Özan ve diğ., 2014) göstermektedir. Ayrıca, bu çalışmaların süreç içine ve çalışma saatleri içine yayılması da önerilmektedir (Boydak-Özan ve diğ., 2014; İlğan, 2013).

Millî Eğitim Bakanlığı'nın [MEB] 2023 Eğitim Vizyonu hedefleri doğrultusunda öğretmenlerin bireysel, mesleki ve alan gelişimlerinin desteklenmesine yönelik etkinlik temelli uygulamaya dayalı yeni bir mesleki gelişim programı hazırlanmıştır (MEB, 2019). Bu kapsamda 2019 tarih ve 30827 sayılı Resmi Gazete'de yayımlanan Millî Eğitim Bakanlığı Okul Öncesi Eğitim ve İlköğretim Kurumları Yönetmeliği’nin 38. Maddesi’nin üçüncü fikrası: "Yönetici ve ögretmenler ara tatillerde, eylül ayının ilk iş gününden derslerin başlangıcına ve derslerin kesiminden temmuz ayının ilk iş gününe kadar geçen süre içerisinde okul müdürlüğü, il/ilçe millî eğitim müdürlüğü veya Bakanlıkça belirlenen mesleki çalışmaları kendi okullarında yürütürler” (Resmi Gazete, 2019a) olarak değiştirilmiştir.

Benzer şekilde, 2019 tarih ve 30829 sayılı Resmi Gazete'de yayımlanan Millî Eğitim Bakanlığı Ortaöğretim Kurumları Yönetmeliği’nin 87. Maddesi: “Ortaöğretim kurumlarında görevli yönetici ve ögretmenler; eylül ayının ilk iş gününden derslerin başlangıç tarihine, derslerin kesimi tarihinden temmuz ayının ilk iş gününe kadar geçen süreler ile kasım ve nisan aylarında yapılacak ara tatillerde, Bakanlıkça hazırlanan program dâhilinde kendi okullarında mesleki çalışma yaparlar” (Resmi Gazete, 2019b) olarak değiştirilmiştir. Bu yönetmeliklerde 
yapılan değişikliklerle birlikte mesleki çalışmaların sadece öğretim yılı başında ve sonunda değil ara tatillerde de yapılmasına karar verilmiştir.

Ayrıca, Kasım dönemindeki ara tatil programı için 2019 tarih ve 30827 sayılı Resmi Gazetede yayımlanan MEB Öğretmenler Günü Yönetmeliği ile de “Öğretmenler Günü dolayısıyla Millî Eğitim Bakanliğı merkez teşkilatı başta olmak üzere il, ilçe, okul ve kurumlar ile yurt dışı temsilciliklerinde oluşturulan kutlama kurullarınca programlar hazırlanır. Hazırlanan programlara göre törenler, sosyal, kültürel ve sportiffaaliyetler, 24 Kasım gününü içine alan hafta boyunca gerçekleştirilir” (Resmi Gazete, 2019c) ibaresine yer verilmiştir. Böylece Öğretmenler Günü kutlaması bir haftaya çıkarılmış oldu. Bu yönetmeliklerde yapılan değişikliklerle “Öğretmen Yetiştirme ve Geliştirme Genel Müdürlüğünce hazırlanan Kasım 2019 mesleki çalışma programı aynı tarihlerde kutlanan 24 Kasım Öğretmenler Günü ve Haftası programının çerçevesinde Öğretmene Vefa temasında” (MEB, 2019) gerçekleştirilmesine karar verilmiştir.

Yeni hazırlanan bu program 2019-2020 eğitim-öğretim yılı Kasım döneminden itibaren uygulamaya konulmuştur. Böylece, mesleki çalışmalar süreç içerisine yayılmıştır. Bilindiği üzere, sene başı ve sene sonu seminerleri ikişer hafta sürüyordu. Bu değişiklikle beraber sene başı ve sene sonu seminerleri birer hafta kısaltılarak, iki haftalık mesleki çalışma programlarının Kasım ve Nisan aylarındaki ara tatillerde birer haftalık dönemlerde yapılmasına karar verilmiştir. Dolayısıyla, 180 iş günü olan çalışma zorunluluğu da değişmemiş oldu, fakat daha önce 13 hafta olan yaz tatili süresi 2 hafta kısaltılarak 11 haftaya indirilmiş oldu. Türkiye'deki tatil süresi uzun yıllardır tartışılagelmiş bir konudur. Bu uygulamayı Avrupa ülkelerindeki uygulamalarla karşılaştıran Doğan (2020) şu sonuçlara varmıştır:

[...]Tüm Avrupa kıtasında birinci dönem ara tatili 19 ülkede, ikinci dönem ikinci ara tatili 20 ülkede uygulanmaktadır. Bu tatili uygulamayan iki ülke olarak Karadağ ve Türkiye vardl. Bu yeni uygulama ile Türkiye [de] diğer Avrupa ülkeleri gibi sonbahar ve ilkbahar ara tatili vermiş oluyor. Bu açıdan bakıldı̆̆ında ise bu uygulamanın bir Avrupa Birliği Uyum Yasaları kapsamında bir çalışma olduğu da söylenebilir. (s. 254)

Alanyazın incelendiğinde, bu değişiklikle ilgili iki çalışma yapıldığı görülmektedir. Bu çalışmalardan biri Doğan (2020) tarafından sınıf öğretmenlerinin ara tatillerle ilgili görüşlerini elde etmek amacıyla yapılmıştır. 15 sınıf öğretmeninin katıldığ 1 bu nitel araştırma sonucunda, öğretmenlerin görüşlerine dayanılarak ara tatillerle ilgili hem olumlu hem de olumsuz bazı bulgulara ulaşılmıştır. 
Diğer bir çalışma ise Kaya (2020) tarafindan ortaokul öğrencilerinin ara tatil uygulamasını nasıl değerlendirdiklerini incelemek amacıyla yapılmıştır. Çalışma sonucunda, öğrencilerin ara tatili verimli geçirdiklerini, ara tatilden genel olarak memnun olduklarını ve ara tatil uygulamasının devam etmesi gerektiğini düşündüklerini gösteren bulgulara ulaşılmıştır.

\section{Araştırmanın Amacı ve Önemi}

Eğitimin en önemli paydaşları en ufak değişiklikten doğrudan etkilenen öğretmen, öğrenci, veli ve okul yöneticileridir. Beraberinde birçok etki getirmesi muhtemel olan bu ara tatil uygulaması hakkında paydaşların görüşlerinin incelenmesi büyük önem arz etmektedir. Yukarıda bahsedildiği gibi sınıf öğretmenleri ve öğrenci görüşlerine dayanılarak yapılmış çalışmalar bulunmaktadır. Ara tatilin, ilkokul, ortaokul ve lise dönemlerindeki paydaşlar tarafından farklı değerlendirilmesi muhtemeldir. $\mathrm{Bu}$ çalışmanın amacı ise ortaokul öğretmenlerinin ara tatil uygulaması hakkındaki görüşlerini incelemektir. Bu bağlamda aşağıdaki sorulara yanıt aranmaya çalışılmıştır:

1. Öğretmenlerin 2019 Kasım dönemi mesleki çalışma programı kapsamındaki etkinlikler hakkındaki görüşleri nelerdir?

2. Öğretmenlerin mesleki çalışma programına eklenmesini istedikleri eğitimler nelerdir?

3. Öğretmenlerin mesleki çalışma programlarının zamanlaması hakkındaki görüşleri nelerdir?

Türkiye'de ara tatilde ilk defa uygulanmış olan mesleki eğitim programı hakkında yapılan bu araştırma ilk araştırmalardan biri olup araştırma bulgularının daha sonraki öğretmen eğitimlerinin planlanmasına katkıda bulunması düşünülmektedir.

\section{Yöntem}

Araştırmanın bu bölümünde araştırmada kullanılan araştırma deseni, katılımcılar, veri toplama aracı ve verilerin analizinde kullanılan teknikler sunulmuştur.

\section{Araştırmanın Deseni}

Gall, Gall ve Borg (2003) tarafından belirtildiği gibi, eğitim araştırması eğitim, öğrenim ve eğitim yönetimi hakkında yeni bilgiler geliştirmek için kullanılır; bu bakımdan çok değerlidir, çünkü bu çalışmalar eninde sonunda eğitim uygulamalarının iyileştirilmesine öncülük edecektir. Bundan dolayı, araştırma desenleri araştırma amacına göre dikkatli bir şekilde seçilmeli ve planlanmalıdır. 
Sosyal ve eğitim dünyası çelişki ve benzerliklerle dolu dağınık bir ortamdır, bu yüzden doğru bir anlayışa sahip olabilmek için parça parça incelemek yerine bütüncül bir anlayışla incelenmelidir (Cohen, Manion ve Morrison, 2007). Bu bağlamda, bu çalışmada, veri çeşitlemesinden faydalanılarak hem nicel hem de nitel metodolojilerin güçlü yanlarından faydalanan (Cresswell, 2009) karma araştırma modeli kullanılmıştır, çünkü her iki metodoloji araştırılan olgunun daha iyi bir şekilde anlaşılmasını sağlar (Fraenkel ve Wallen, 2012).

Alanyazında birçok karma yöntem tasarımı bulunmaktadır. Cresswell (2009) altı çeşit karma yöntem önermektedir. Bu farklılıklar aslında verileri toplama sırasına (timing), hangi verinin daha önemli olduğu (weighting), verilerin nerede ve ne zaman birleştirildiği (mixing) ve bir teorinin çalışmayı yönlendirip yönlendirmediği (theorizing) gibi dört boyuta bağlıdır (Cresswell, 2009).

Bu çalışmada Creswell (2009) tarafindan önerilen eşzamanlı gömülü strateji (concurrent embedded strategy) kullanılmıştır. Bu stratejinin temel özelliği araştırmayı yönlendiren birincil bir yöntemin yanında destekleyici bir rol sağlayan ikincil bir verinin kullanılabilmesidir. İkincil yöntem, birincil yöntemin içine gömülür; bu da ikincil yöntemin, birincil yöntemden farklı bir soruya cevap arayabileceği anlamına gelir. Nicel ve nitel verilerin birleştirilmesi üç şekilde gerçekleşir; veriler birbirini tamamlamak için birleştirilebilir, birbirleriyle karşılaştırılabilir veya ikincil veriler araştırılmakta olan olgunun başka bir yönünü sunmak için kullanılabilir.

$\mathrm{Bu}$ çalışmada nicel ve nitel veriler aynı veri toplama aracıyla eşzamanlı toplanmış ve nitel veriler hem nicel verileri tamamlamak için hem de araştırılan olgunun farklı bir yönünü inceleyip sunmak için kullanılmıştır.

\section{Evren ve Örneklem}

Araştırmanın evrenini Ağrı il merkezindeki 42 okulda çalışan 1014 ortaokul öğretmeni oluşturmaktadır. Çalışma için gerekli olan örneklem büyüklüğü, Bartlett, Kotrlik ve Higgins (2001) tarafından önerilen aşağıdaki formüle göre hesaplanmıştır:

$$
\begin{aligned}
& \mathrm{n}_{0}=\frac{(\mathrm{t})^{2} \times(\mathrm{p})(\mathrm{q})}{(\mathrm{d})^{2}} \\
& \mathrm{n} 1=\frac{\mathrm{n}_{0}}{1+\mathrm{n}_{0} / \text { Evren }}
\end{aligned}
$$


Yapılan hesaplama sonucunda Ağrı merkezde çalışan öğretmen evreni için gerekli örneklem büyüklüğü 277 olarak bulunmuştur. Örneklem seçiminde seçkisiz örnekleme yöntemlerinden biri olan küme örnekleme yöntemi kullanılmıştır. Bu yöntemle 42 okula numara verilmiş ve kura ile seçilen okullarda çalışan bütün öğretmenler çalışmanın örnekleminde yer almıştır. Bilindiği üzere, her okulun öğretmen sayısı birbirinden farklıdır, dolayısıyla seçilen okullarda çalışan öğretmen sayısı 278'i bulana kadar kuraya devam edilmiştir. Sonuç olarak, kura sonucu 14 okul seçilmiş ve bu okullarda çalışan 302 öğretmene anket dağıtılmıştır. $\mathrm{Bu}$ öğretmenlerden 281 tanesi anketi doldurarak teslim etmiştir. Dolayısıyla, bu çalışmanın örneklemi 281 öğretmenden oluşmaktadır. Tablo 1'de çalışmaya katılan öğretmenlerin kişisel özellikleri ile ilgili bilgiler sunulmuştur. Tabloda görüldüğü üzere kadın öğretmenlerin sayısı (\%55.5) erkek öğretmenlerin sayısından (\%45.5) daha fazladır. Öğretmenlerin yaş ortalaması 31 iken, yaklaşık yarısının (\%46) 1 ila 5 yıllık öğretmenlik deneyimine sahip olduğu görülmektedir.

Tablo 1. Ankete Katılan Öğretmenlerin Demografik Özellikleri

\begin{tabular}{lllll}
\hline Değişken & Grup & $\boldsymbol{f}$ & $\mathbf{\%}$ & $\boldsymbol{X}$ \\
\hline Cinsiyet & Kadın & 156 & 55.5 \\
& Erkek & 125 & 44.5 \\
\hline Yaş & & & & 31 \\
\hline Eğitim Seviyesi & Lisans & 270 & 97 & \\
& Yüksek lisans & 10 & 2.7 \\
& Doktora & 1 & .3 \\
\hline Branş & Türkçe & 56 & 19 \\
& Matematik & 37 & 13 \\
& Fen Bilgisi & 40 & 14 \\
& Sosyal Bilgiler & 28 & 10 \\
& İngilizce & 36 & 13 \\
& Rehberlik & 16 & 6 \\
& Beden Eğitimi ve Spor & 17 & 6 \\
& Din Kült. ve Ahlak Bilgisi & 19 & 7 \\
& Bilişim Teknolojileri & 8 & 3 \\
& Teknoloji ve Tasarım & 8 & 3 \\
& Müzik & 12 & 4 \\
& Görsel Sanatlar & 4 & 2 \\
\hline Mesleki Deneyim & 1-5 Yıl & 130 & 46 \\
& 6-10 Yil & 83 & 30 \\
& 11-15 Yil & 32 & 11 \\
& 16 Yil ve üzeri & 36 & 13 \\
\hline
\end{tabular}

Eğitim seviyesine bakıldığında büyük bir çoğunluğun (\%97) lisans derecesine sahip olduğu görülmektedir. Katılımcıların branş bazında dağılımlarına bakıldığında en büyük orana Türkçe öğretmenlerinin (\%19) sahip olduğu, Görsel Sanatlar öğretmenlerinin (\%2) ise en küçük orana sahip olduğu görülmektedir. 


\section{Veri Toplama Araçları}

Araştırma sorularına yanıt bulmak için araştırmacı tarafından yarı yapılandırılmış bir anket geliştirilmiştir. Anket geliştirme sürecinde öncelikle MEB (2019) tarafından yayımlanan sosyal, sanatsal, sportif, sosyal-kültürel vb. etkinliklerin yer aldığı 2019 Kasım dönemi mesleki çalışma programı incelenmiştir. Hazırlanan anketin, birinci bölümünde kişisel bilgiler, üç alt bölümden oluşan ikinci bölümünün ilk alt bölümünde öğretmenlerin etkinlikler hakkındaki görüşleri ile ilgili maddeler yer almış, ikinci alt bölümünde etkinlik temelli bir çalışma programı olmasına rağmen öğretmenlerin ihtiyaç duyulan eğitimler hakkındaki görüşleri ile ilgili maddeler, üçüncü ve son alt bölümde ise öğretmenlerin mesleki çalışmanın zamanlaması hakkındaki görüşlerini almak için bazı maddeler ve alt sorulardan oluşan açik uçlu bir soru sorulmuştur.

Anketin ikinci bölümünün ilk alt bölümüne madde yazılırken öncelikle mesleki çalışma programı incelenmiştir. Daha sonra, ortaokulda görev yapmakta olan beş öğretmen ile görüşmeler yapılmıştır. Yapılan görüşmeler içerik analizine tabii tutulmuş, analizden elde edilen kodlamalarla etkinlikler ile ilgili maddeler yazılmıştır. Taslak olarak yazılan 19 maddenin kapsam geçerliğine sahip olup olmadığını öğrenmek için iki uzmanın görüşüne sunulmuştur, uzman görüşlerine dayanarak altı madde çıkarılmış, bazı maddeler ise tekrar düzenlenmiştir. Daha sonra, maddelerin anlaşılırlığını ölçmek için, anket altı öğretmene inceletilmiş ve maddelerin anlaşılır olduğu görülmüştür.

Mesleki çalışmanın zamanı ve ihtiyaç duyulan eğitimler bölümü hazırlanırken önce ilgili alanyazın incelenmiş (Akar, 2006; Boydak-Özan ve diğ., 2014; Ceylan ve Özdemir, 2016; Gültekin ve Çubukçu, 2008; Gümüş, 2006; Öztürk ve Sancak, 2007; Tonbul, 2004) ve nitel olarak ulaşılan sonuçlara dayanılarak maddeler yazılmıştır. Aynı şekilde, anketin bu bölümüne de uzman görüşlerine bağlı olarak gerekli düzeltme ve düzenlemeler yapılarak kapsam geçerliği sağlanmıştır. Anketi inceleyen altı öğretmen maddeleri okumuş ve anlaşılırlık konusunda herhangi bir soruna rastlanmamıştır. Son olarak, iç tutarlılığını ölçmek için anket 68 öğretmene uygulanmıştır. Anketin etkinliklerle ilgili görüşler, ihtiyaç duyulan eğitimler ile ilgili görüşler ve mesleki çalışmanın zamanlaması isimli alt bölümleri için bulunan Cronbach Alfa değerleri sırasıyla $.89, .92$ ve .84 olarak bulunmuştur. Bu değerler, anketin iyi bir güvenirliğe sahip olduğunu göstermektedir (George ve Mallery, 2003).

$\mathrm{Bu}$ süreçlerden sonra son hali verilen anketin ikinci bölümü toplam 25 madde ve açık uçlu bir sorudan oluşmuştur. Anket, beş puanlık Likert ölçeğinde modellenmiş ve 
öğretmenlerden, verilen ifadelere katılma ya da katılmama seviyelerini 1 ile 5 arasında derecelendirmeleri istenmiştir (1 - kesinlikle katılmıyorum, 5 - kesinlikle katılıyorum).

\section{Verilerin Analizi}

Araştırmada elde edilen nicel veriler ortalama, frekans ve yüzdeliklerle incelenmiştir. Öğretmenlerin tablodaki maddeleri derecelendirmeleri sunulurken, maddelere "kesinlikle katıliyorum" ve "katılıyorum" derecelerine verilen yanitlar toplanırken, "kesinlikle katılmıyorum" ve "katılmıyorum" dereceleri de kendi aralarında toplanarak sunulmuştur. Böylece görüşler "olumlu” veya "olumsuz" olarak nitelendirilmiştir.

Nitel veriler ise içerik analizi ile incelenmiştir. Creswell'in (2009) belirttiği gibi nitel veriler incelenirken kullanılan araştırma desenine bağlı olarak farklı kodlama yöntemleri kullanılmakta, ancak, nitel veri analizinde yaygın ve ortak olan araştırmacının topladığ 1 verileri temalar için analiz ettiği ve bu temaları sunduğudur. Bu çalışmada da elde edilen veriler derinlemesine incelenerek, kodlar ve temalara ulaşılmıştır. Ham verilerin eşzamanlı olarak kodlanmasını ve belgenin içeriğinin benzer özelliklerini yakalayan kategorilerin oluşturulmasını içeren (Merriam, 2009, s. 205) içerik analizi sürecine veriyi genel olarak anlamak ve üzerinde derinlemesine düşünmek için ham veriler ilk olarak birkaç kez okunmuştur (Creswell, 2009). Kodlar oluşturulurken, bazen paragraflar, bazen cümleler ve bazen de belli kelimeler kullanılmıştır. Daha sonra, cümleler veya ifadeler kodlara dönüştürülmüş ve bunlara bir isim verilmiştir, son olarak kodlar temalar altında toplanmıştır (Creswell, 2009).

Analiz sürecinde, öğretmenlere “Ö1, Ö2, ...Ö281” gibi kod numaraları verilmiş ve öğretmenlerin görüşlerini açık ve net bir şekilde yansıtabilmek amacıyla bulgular gerektiğinde doğrudan alıntılarla desteklenmiştir. Araştırmanın dış güvenirliğini ölçmek amacıyla rastgele seçilmiş iki anket, birbirinden bağımsız iki kodlayıcıya gönderilmiş ve metinleri kodlamaları istenmiştir. Miles ve Huberman'ın (1994) önerdiği (Güvenirlik=Görüş birliği/görüş birliği+görüş ayrıllğı) formül kullanılarak hesaplananan kodlayıcılar arası güvenirlik değeri ve uyum birinci metin için \%79, ikinci metin içinse \%84 olarak bulunmuştur. Bu sonuçlar kodlamaların yeterli düzeyde güvenilir olduğunu göstermektedir (Miles ve Huberman, 1994).

\section{Etik Kurul Kararı}

Ağrı İbrahim Çeçen Üniversitesi Bilimsel Araştırmalar Etik Kurulu'nun, 08/09/2020 tarih ve 115 sayılı kararı gereği, İbrahim Çeçen Üniversitesi Bilimsel Araştırmalar Etik Kurulu Yönergesi madde 3, 9, 10, 11, 12 ve 13'e çerçevesinde çalışmada herhangi bir sakınca olmadığına oy birliğiyle karar verilmiştir. 


\section{Bulgular}

Bu bölümde araştırma sorularına yönelik ulaşılan bulgular yer almaktadır. İlk araştırma sorusu olan "Öğretmenlerin 2019 Kasım dönemi mesleki çalışma programı kapsamındaki etkinlikler hakkındaki görüşleri” ile ilgili bulgular aşağıda sunulmuştur.

Tablo 2'de öğretmenlerin mesleki eğitim programı çerçevesinde kendilerine sunulan etkinlik ve faaliyetler hakkındaki görüşlerinin derecelendirildiği bulguların yüzde ve frekansları sunulmaktadır. Tabloya bakıldığında, öğretmenlerin \% $72.9(f=205)$ ile \% 97.1'inin $(f=273)$, tablodaki etkinliklerle ilgili olumlu yönde görüş belirttikleri görülmektedir. Daha açık bir şekilde ifade etmek gerekirse, tabloda görüldüğü üzere "etkinlikler, planlandığı gibi uygulanmıştır” maddesi için öğretmenlerin onda dokuzundan fazlası (\%94) olumlu yönde görüş belirtirken, "etkinlikler, beklentilerimi karş1lamıştır” maddesi için öğretmenlerin beşte dördünden fazlası (\%85.5); “etkinlikler, amacına uygun yapılmıştır” maddesi için öğretmenlerin beşte dördünden fazlası (\%87.2) olumlu yönde görüş belirtmiştir.

Tablo 2. Öğretmenlerin Etkinlik ve Faaliyetler Hakkındaki Görüşleri

\begin{tabular}{|c|c|c|c|c|c|c|c|c|c|c|}
\hline & 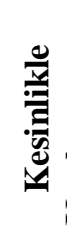 & & 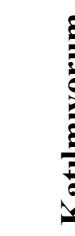 & 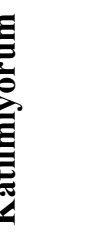 & 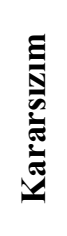 & & E & & 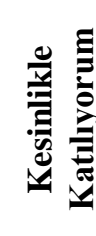 & \\
\hline Etkinlikler... & $f$ & $\%$ & $f$ & $\%$ & $f$ & $\%$ & $f$ & $\%$ & $f$ & $\%$ \\
\hline 1. planlandığı gibi uygulanmıştır. & 0 & 0 & 0 & 0 & 16 & 6 & 115 & 41 & 150 & 53 \\
\hline 2. beklentilerimi karşılamıștır. & 8 & 2.8 & 4 & 1.4 & 28 & 10 & 132 & 47 & 109 & 38.8 \\
\hline 3. amacına uygun yapılmıştır. & 4 & 1.4 & 8 & 2.8 & 24 & 8.5 & 132 & 47 & 113 & 40.2 \\
\hline $\begin{array}{l}\text { 4. çalışma ortamımda sosyalleşmemi } \\
\text { sağlamıştır. }\end{array}$ & 0 & 0 & 4. & 1.4 & 16 & 5.7 & 131 & 46.6 & 130 & 46.3 \\
\hline $\begin{array}{l}\text { 5. çalıştığım kuruma karşı olumlu tutum } \\
\text { geliştirmemi sağlamıştır. }\end{array}$ & 0 & 0 & 0 & 0 & 8 & 2.8 & 135 & 48 & 138 & 49.1 \\
\hline $\begin{array}{l}\text { 6. çalıştı̆̆ım kuruma karşı aitlik duygumu } \\
\text { geliştirmiştir. }\end{array}$ & 0 & 0 & 8 & 2.8 & 16 & 5.7 & 123 & 43.8 & 134 & 47.7 \\
\hline 7. verimli geçmiştir. & 4 & 1.4 & 44 & 15.7 & 28 & 10 & 65 & 23.1 & 140 & 49.8 \\
\hline 8. yenilenmemi sağlamıştır. & 12 & 4.3 & 8 & 2.8 & 20 & 7.1 & 160 & 56.9 & 81 & 28.8 \\
\hline 9. ilgi çekiciydi. & 0 & 0 & 4 & 1.4 & 20 & 7.1 & 144 & 51.2 & 113 & 40.2 \\
\hline $\begin{array}{l}\text { 10. meslektaşlarımı yakından tanımamı } \\
\text { sağlamıştır. }\end{array}$ & 0 & 0 & 0 & 0 & 21 & 7.5 & 175 & 62.3 & 85 & 30.2 \\
\hline $\begin{array}{l}\text { 11. çalıştığım bölgeyi daha iyi tanımamı } \\
\text { sağlamıştır. }\end{array}$ & 0 & 0 & 4 & 1.4 & 32 & 11.4 & 165 & 58.7 & 80 & 28.5 \\
\hline $\begin{array}{l}\text { 12. çalıştığım bölgenin tarihi, doğal ve } \\
\text { kültürel özelliklerini öğrenmemi sağlamıştır. }\end{array}$ & 0 & 0 & 16 & 5.7 & 52 & 18.5 & 149 & 53 & 64 & 22.8 \\
\hline 13. genel olarak beni mutlu etmiştir. & 4 & 1.4 & 0 & 0 & 12 & 4.3 & 144 & 51.2 & 121 & 43.1 \\
\hline
\end{tabular}

"Etkinlikler, çalışma ortamımda sosyalleşmemi sağlamıştır” maddesi için öğretmenlerin onda dokuzundan fazlası (\%92.9) olumlu yönde görüş belirtirken; “etkinlikler, çalıştığım 
kuruma karşı olumlu tutum geliştirmemi sağlamıştır” maddesi için öğretmenlerin hemen hemen hepsi (\%97.1); “etkinlikler, çalıştığım kuruma karşı aitlik duygumu geliştirmiştir” maddesi için öğretmenlerin onda dokuzundan fazlası (\%91.5); “etkinlikler, verimli geçmiştir” maddesi için öğretmenlerin yaklaşık dörtte üçü (\%72.9); “etkinlikler, yenilenmemi sağlamıştır” maddesi için öğretmenlerin beşte dördünden fazlası (\%85.7); “etkinlikler, ilgi çekiciydi” maddesi için öğretmenlerin onda dokuzundan fazlası (\%91.4); “etkinlikler, meslektaşlarımı yakından tanımamı sağlamıştır” maddesi için öğretmenlerin onda dokuzundan fazlası (\%92.5); “etkinlikler, çalıştığım bölgeyi daha iyi tanımamı sağlamıştır” maddesi için öğretmenlerin yaklaşık onda dokuzu (\%87.2); “etkinlikler, çalıştığım bölgenin tarihi, doğal ve kültürel özelliklerini öğrenmemi sağlamıştır” maddesi için öğretmenlerin onda dokuzundan fazlası (\%75.8); son olarak, “etkinlikler, genel olarak beni mutlu etmiştir” maddesi için öğretmenlerin onda dokuzundan fazlası (\%94.3) olumlu yönde görüş belirtmiştir. Bu bağlamda, en fazla olumlu görüş bildirilen maddenin "etkinlikler, çalıştığım kuruma karşı olumlu tutum geliştirmemi sağlamıştır” maddesi (\%97.1) olurken, "etkinlikler, verimli geçmiştir” maddesi $(\% 72.9)$ ise en az olumlu görüş bildirilen madde olarak göze çarpmaktadır. Diğer yandan, öğretmenlerin \% $0(f=0)$ ila \% 17.1'inin $(f=48)$ ise bu etkinliklerle ilgili olumsuz yönde görüş belirttiği ve \% $2.8(f=8)$ ila \% 18.5'inin $(f=52)$ ise bu maddelerle ilgili kararsız oldukları görülmektedir.

2019 Kasım Dönemi Mesleki Çalışma Programı etkinlik temelli bir program olmasına rağmen öğretmenlere bu dönemde mesleki eğitim verilip verilmemesi ile ilgili görüşleri sorulmuştur. Çalışmaya katılan 281 öğretmenin dörtte üçünden fazlası $(f=220, \% 78.3)$ bu soruya olumlu yanıt verirken, beşte birinden fazlası $(f=61, \% 21.7)$ eğitim eklenmesine karşı çıktığını belirtmiştir. Bu soruya olumlu yanıt veren öğretmenlerin bu dönemde verilmesini istedikleri eğitimler ile ilgili bulgular Tablo 3 'te verilmiştir.

Tabloda görüldüğü üzere, ölçme-değerlendirme eğitimi için öğretmenlerin beşte ikisinden fazlası (\%43.1) olumlu görüş belirtirken, yaklaşı üçte biri (\%31.4) olumsuz görüş belirtmiş, \%5.3'ü ise bu konuda kararsız olduğunu belirtmiştir. Yaratıcı drama konusunda öğretmenlerin yaklaşık üçte ikisi (\%69.4) olumlu görüş belirtirken, \%6's1 olumsuz görüş belirtmiş, \%2.8'i ise bu konuda kararsız olduğunu belirtmiştir. Materyal geliştirme eğitimi için öğretmenlerin beşte üçünden fazlası (\%61.2) olumlu görüş belirtirken, yaklaşık onda biri (\%9.9) olumsuz görüş belirtmiş, \% 7.1'i ise bu konuda kararsız olduğunu belirtmiştir. 
Tablo 3. Öğretmenlerin İhtiyaç Duyulan Mesleki Çalışmalar Hakkındaki Görüşleri

\begin{tabular}{|c|c|c|c|c|c|c|c|c|c|c|}
\hline \multirow[t]{2}{*}{ Mesleki Eğitimler } & \multicolumn{2}{|c|}{ 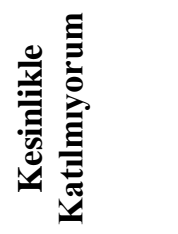 } & \multicolumn{2}{|c|}{ ह̇ } & \multicolumn{2}{|l|}{ 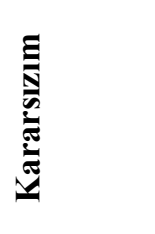 } & \multicolumn{2}{|c|}{ 竭 } & \multicolumn{2}{|c|}{ 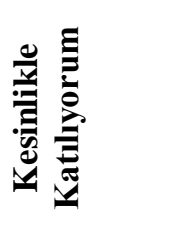 } \\
\hline & $f$ & $\%$ & $f$ & $\%$ & $f$ & $\%$ & $f$ & $\%$ & $f$ & $\%$ \\
\hline 1. Ölçme-değerlendirme & 44 & 15.7 & 44 & 15.7 & 15 & 5.3 & 60 & 21.4 & 61 & 21.7 \\
\hline 2. Yaratıcı drama & 9 & 3.2 & 8 & 2.8 & 8 & 2.8 & 91 & 32.4 & 104 & 37 \\
\hline 3. Materyal geliştirme & 24 & 8.5 & 4 & 1.4 & 20 & 7.1 & 67 & 23.8 & 105 & 37.4 \\
\hline 4. Ders programı hazırlama & 36 & 12.8 & 28 & 10 & 31 & 11 & 44 & 15.7 & 81 & 28.8 \\
\hline 5. Bilişim teknolojileri & 29 & 10.3 & 8 & 2.8 & 24 & 8.5 & 63 & 22.4 & 96 & 34.2 \\
\hline
\end{tabular}

Ders programı hazırlama konusunda öğretmenlerin yaklaşık yarısı (\%44.5) olumlu görüş belirtirken, yaklaşık dörtte biri (\%22.8) olumsuz görüş belirtmiş, \%11'i ise bu konuda kararsız olduğunu belirtmiştir. Son olarak, bilişim teknolojileri eğitimi için öğretmenlerin yarısından fazlası (\%56.6) olumlu görüş belirtirken, onda birinden fazlası (\%13.1) olumsuz görüş belirtmiş, \%8.5'i ise bu konuda kararsız olduğunu belirtmiştir.

Tablo 4'te öğretmenlerin mesleki eğitimin zamanlaması hakkındaki görüşleri ile ilgili bulgular sunulmaktadır. Tabloda görüldüğü gibi, "mesleki eğitimler sadece sene sonunda yapılmalıdır" önermesi için öğretmenlerin yaklaşık beşte biri (\%18.5) olumlu görüş belirtirken, beşte üçünden fazlası (\%64.4) olumsuz görüş belirtmiş ve \%17.1’i kararsız kaldığını belirtmiştir.

Tablo 4. Öğretmenlerin Mesleki Eğitimin Zamanlaması Hakkındaki Görüşleri

\begin{tabular}{|c|c|c|c|c|c|c|c|c|c|c|}
\hline \multirow[b]{2}{*}{ Mesleki eğitimler... } & \multicolumn{2}{|c|}{ 宽 } & \multicolumn{2}{|c|}{ 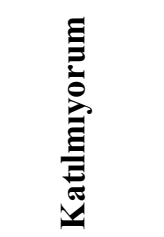 } & \multirow{2}{*}{ 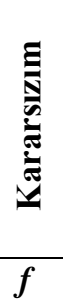 } & \multicolumn{3}{|c|}{ 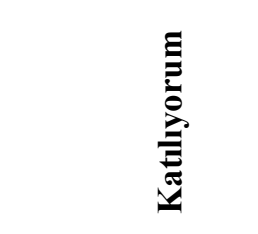 } & \multicolumn{2}{|c|}{ 吾 } \\
\hline & $f$ & $\%$ & $f$ & $\%$ & & $\%$ & $f$ & $\%$ & $f$ & $\%$ \\
\hline 1. sadece sene sonunda yapılmalıdır. & 96 & 34.2 & 85 & 30.2 & 48 & 17.1 & 12 & 4.3 & 40 & 14.2 \\
\hline 2. sadece sene başında yapılmalıdır. & 96 & 34.2 & 93 & 33.1 & 44 & 15.7 & 16 & 5.7 & 32 & 11.4 \\
\hline $\begin{array}{l}\text { 3. sadece sene başında ve sene sonunda } \\
\text { yapılmalıdır. }\end{array}$ & 84 & 29.9 & 89 & 31.7 & 44 & 15.7 & 20 & 7.1 & 44 & 15.7 \\
\hline 4. sadece ara tatillerde yapılmalıdır. & 88 & 31.3 & 96 & 34.2 & 40 & 14.2 & 33 & 11.7 & 24 & 8.5 \\
\hline $\begin{array}{l}\text { 5. sene başı, ara tatiller ve sene sonunda } \\
\text { yapılmalıdır. }\end{array}$ & 78 & 27.3 & 33 & 11.7 & 28 & 10 & 66 & 24 & 76 & 27 \\
\hline 6. ihtiyaç duyulduğunda yapılmalıdır. & 72 & 25.6 & 49 & 17.4 & 44 & 15.7 & 52 & 18.5 & 64 & 22.8 \\
\hline 7. kaldırılmalıdır. & 136 & 48.4 & 73 & 26 & 48 & 17.1 & 8 & 2.8 & 16 & 5.7 \\
\hline
\end{tabular}

"Mesleki eğitimler sadece sene başında yapılmalıdır" önermesi için öğretmenlerin yaklaşık beşte biri (\%17.1) olumlu görüş belirtirken, üçte ikisinden fazlası (\%67.3) olumsuz 
görüş belirtmiş ve \%15.7'si kararsız kaldığını belirtmiştir. "Mesleki eğitimler sadece sene başında ve sene sonunda yapılmalıdır” önermesi için öğretmenlerin beşte birinden fazlası (\%22.7) olumlu görüş belirtirken, üçte ikisinden fazlası (\%61.6) olumsuz görüş belirtmiş ve \%15.7'si kararsız kaldığını belirtmiştir. "Mesleki eğitimler sadece ara tatillerde yapılmalıdır" önermesi için öğretmenlerin beşte birinden fazlası (\%20.2) olumlu görüş belirtirken, beşte üçünden fazlası (\%65.5) olumsuz görüş belirtmiş ve onda birinden fazlası (\%14.2) kararsız kaldığını belirtmiştir. "Mesleki eğitimler sene başı, ara tatiller ve sene sonunda yapılmalıdır" önermesi için öğretmenlerin yarısından fazlası (\%51) olumlu görüş belirtirken, yaklaşık beşte ikisi (\%39) olumsuz görüş belirtmiş ve onda biri (\%10) kararsız kaldığını belirtmiştir. "Mesleki eğitimler ihtiyaç duyulduğunda yapılmalıdır” önermesi için öğretmenlerin beşte ikisinden fazlası (\%41.3) olumlu görüş belirtirken, aynı şekilde beşte ikisinden fazlası (\%43) olumsuz görüş belirtmiş ve \%15.7'si kararsız kaldığını belirtmiştir. Son olarak, "Mesleki eğitimler kaldırılmalıdır" önermesi için öğretmenlerin yaklaşık onda biri (\%8.5) olumlu görüş belirtirken, yaklaşık dörtte üçü (\%74.4) olumsuz görüş belirtmiş ve \%17.1'i kararsız kaldığını belirtmiştir.

Anketin bu bölümünün sonuna öğretmenlere "Mesleki çalışmanın ara tatilde verilmesini nasıl değerlendiriyorsunuz?" ana sorusuyla birlikte "Sizce olumlu ve olumsuz yönleri nelerdir? Ara tatil mesleki çalışma programına ilişkin önerileriniz nelerdir?” alt soruları yöneltilmiş fakat bu bölümü sadece 56 öğretmen doldurmuştur. Verilen cevaplara uygulanan içerik analizi sonucu üç temaya ulaşılmıştır. Ulaşılan temalar ve temaları oluşturan kodlar Tablo 5'te sunulmuştur.

Tablo 5'te görüldüğü üzere, ara tatilin olumlu yönlerine yönelik görüş bildiren öğretmenler, mesleki çalışmanın ara tatilde yapılmasının daha etkili, daha eğlenceli, dinlendirici, rahatlatıcı ve motivasyon arttırıcı bulmuş, bu sayede enerji depoladıklarını ve bir durum değerlendirmesi yapma firsatı elde ettiklerini belirtmişlerdir.

Bir öğretmen önyargılarının ve beklentilerinin aksine memnuniyetini ve şaşkınlığını şu ifadelere yer vermiştir:

"Ĕgitim-öğretime kısa bir ara, bir nefes niteliğinde olması bizlerin derslere daha motive edici olmamızı sağlamıştır. Hatta başta böyle duygular içinde olabileceğimi hiç tahmin etmemiştim. Şaşırdım açıkçası. Lütfen devam etsin...” (Ö155) 
Tablo 5. Öğretmenlerin Mesleki Çalışmanın Ara Tatilde Yapılması ile İlgili Ulaşılan Tema ve Kategoriler

\begin{tabular}{ll}
\hline Temalar & \multicolumn{1}{c}{ Kodlar } \\
\hline 1. Olumlu Görüşler & 1.1. Daha etkili \\
1.2. Eğlenceli & 1.3. Uygulanışı \\
1.4. Dinlendirici \\
1.5. Enerji depolama \\
1.6. Motivasyon artışı \\
1.7. Rahatlatıcı \\
1.8. Durum değerlendirmesi firsatı \\
2.1. Öğrencilerin dersten kopması \\
2.2. Öğrencilerin derse adapte olamaması \\
2.3. Öğrencilerin uyku problemi \\
3.1. Daha hafif program \\
3.2. Zümre bazlı eğitim \\
3.3. Farklı illerde katılım \\
3.4. İhtiyaç duyulduğunda yapılması \\
3.5. Etkinliklerin daha erken duyurulması \\
3.6. Öğrenci katılımı sağlanmalı \\
3.7. Öğrencilerle geziler \\
3.8. Mesleki geziler \\
3.9. Farklı illerde düzenleme \\
3.10. Okula gelinmemeli \\
3.11. Devam etmeli \\
3.12. Bölgesel farklılıklar \\
3.13. İhtiyaca yönelik \\
3.14. Uzman eğitimciler \\
\hline
\end{tabular}

Bazı öğretmenler memnuniyetlerini şu şekilde belirtmiştir:

“Ara dönem kısa bir dinlenme molası olarak değerlendirilebilir. Özellikle sinav yorgunluğu artan öğrenciler ve ögrretmenler için olumlu buluyorum. Çünkü o döneme girmeden 1. yazılı yoklamalar yapılmış oluyor. Dolayısıla ara dinlenme faydalı oluyor." (Ö34)

"Ara tatil yapılıp mesleki çalışma yapılması benim için rahatlatıcı oldu. Ben bu çalışmalardan çok memnun oldum. Bir dezavantaj görmüyorum. Arkadaşlarımızla yaptı̆̆ımı güncel diyaloglar ve etkinlikler çok keyifli vakit geçirmemizi sağladı." (Ö218)

“Ara tatil her türlü avantajll ve olumludur.” (Ö15)

Bir öğretmen ara tatildeki programı sene başı ve sene programlarla karşılaştırarak aşağıdaki ifadelere yer vermiştir:

"Sene başı ve sene sonu seminerlerinin uzun olması verimsizliğe sebep oluyordu, o seminerler formaliteden öteye geçemiyordu. Çoğu şeyi “mış” gibi yapıyorduk. Çok boş 
geçiyordu. Saatlerce okulda boş boş beklerdik. Bu program gerçekten uygulandı. Hem de çok güzel...” (Ö241)

Bazı öğretmenler de ara tatil mesleki çalışmalarının devam etmesi gerektiğini şu sözlerle ifade etmişlerdir:

"Bütün mesleki çalışmaların daha çok sosyal faaliyetler üzerinden uygulanması taraftarlyım. Gayet olumlu bir ara tatil ve mesleki çalışma süreci geçirdik. Geliştirilerek devam eder diye umuyorum.”(Ö148)

"Ara tatil hem ögrrenciler hem de öğretmenler için çok güzel bir mola olmuştur. Hepimizin buna ihtiyacı varmış. Devamını diliyorum." (Ö27)

Tablo 5'te görüldüğü gibi, öğretmenler ara tatil mesleki çalışma programı ile ilgili bazı olumsuz fikirler de belirtmişlerdir. Olumsuz görüşlere bakıldığında, öğrencilerin derslerden kopması, öğrencilerin tatilden sonra derslere adapte olmakta zorluk çekmesi ve öğrencilerin uyku problemi yaşamaları gibi tamamen öğrencilerle ilgili olumsuz görüş belirttikleri görülmüştür. $\mathrm{Bu}$ duruma ilişkin görüş belirten katılımcıların görüşlerinden çarpıcı olanlara aşağıda yer verilmiştir.

"Bizim açımızdan sorun yok ama ögrenciyi toparlamak ve derse adapte etmek konusunda sıkıntılar yaşandı.” (Ö101)

"Bizim için her şey çok güzeldi ancak tatil dönüşü ögrencilerin tekrar okula adapte olmasl zor oluyor. " (Ö253)

Tablo 5'te sunulduğu üzere öğretmenler ara tatil mesleki eğitim programı ile ilgili birçok öneride de bulunmuştur. Öğretmenlerin, mesleki çalışmalar için daha hafif bir program hazırlanması, zümre bazlı eğitim verilmesi, yapılan eğitim ve etkinliklere farklı illerde katılımın mümkün kılınması, ihtiyaç duyulduğu zamanlarda yapılması, program ve etkinliklerin daha erken duyurulması, etkinliklere öğrenci katılımının sağlanması, öğrencilerle şehir içi ve şehirler arası geziler düzenlenmesi, mesleki geziler düzenlenmesi, farklı illerde farklı etkinlikler düzenlenmesi, öğretmenlerin okula gelmemeleri, ara tatil verilirken bölgesel farklılıkların göz önünde bulundurulması, ihtiyaca yönelik eğitimler hazırlanması, eğitimlerin alanında uzman kişilerce verilmesi ve ara tatilde mesleki çalışma programlarına devam edilmesi gerektiği yönünde görüş belirtmişlerdir. Bazı görüşler aşağıda sunulmuştur:

“Ara seminerlerde ögrretmenlerin de dinlenmeye ihtiyacı olduğu düşünülerek daha hafif bir program hazırlanabilir." (Ö211) 
"Mesleki çalışma programları için eğitimler hazırlanırken, il genelinde bölümlere ayrılabilir. Haftalık çalışma yapılıp öğretmenler istedikleri eğitimlere gidebilir. Herkesin ayn şeye ihtiyacı olmayabilir. İlimiz genelinde gruplama yapılarak eğitim planlanabilir. Herkes ihtiyacı olan bir eğitime giderse daha faydalı ve verimli olacaktır."(Ö124)

"Daha iyi bir uygulama için gerçekten alanında uzman eğitimcilerden yüz yüze ĕgitimler alınmalı." (Ö96)

\section{Tartışma, Sonuç ve Öneriler}

$\mathrm{Bu}$ bölümde araştırma sorularına yönelik elde edilen bulgulardan hareketle ulaşılan sonuçlar sunulmaktadır. Anketin birinci alt bölümü olan öğretmenlerin etkinliklerle ilgili görüşlerini kapsayan bulgular, etkinliklerin planlandığg gibi uygulandığını, ilgi çekici olduğunu, verimli geçtiğini, beklentileri karşıladığını ve Boydak-Özan vd. (2014) tarafından yapılan çalışmanın aksine, bu programın amacına uygun yapıldığını göstermektedir. $\mathrm{Bu}$ bulgulardan yola çıkarak etkinlik seçiminde başarılı olunduğu sonucuna varılabilir. Ayrıca, öğretmenlerin seminer çalışmalarını bir formalite olarak gördüğü sonucuna varan çalışmaların (Ceylan ve Özdemir, 2016; Tonbul, 2004) aksine bu araştırma programın planlandığı gibi uygulandığını göstermektedir.

Etkinliklerin öğretmenler üzerinde de bazı etkiler gösterdiğini söylemek mümkündür. Bulgular incelendiğinde, etkinliklerin öğretmenlerin çalışma ortamlarında sosyalleşmelerini sağladığını, çalıştıkları kurumlarına karşı olumlu tutum geliştirmelerini sağladığını, çalıştıkları kuruma karşı aitlik duygularını geliştirdiğini, meslektaşlarını yakından tanımalarını sağladığını, çalıştıkları bölgeyi daha iyi tanımalarını sağladığını, çalıştıkları bölgenin tarihi, doğal ve kültürel özelliklerini öğrenmelerini sağladığını, yenilenmelerini sağladığını ve öğretmenleri genel olarak mutlu ettiğini söylemek mümkündür. Öğretmenlerin mesleki eğitim programı çerçevesinde kendilerine sunulan etkinlik ve faaliyetler hakkındaki görüşlerine yönelik bulgulardan yola çıkarak öğretmenlerin memnuniyet derecelerinin oldukça yüksek olduğu sonucuna var1labilir.

Yukarıda bahsedilen olumlu görüşlere ek olarak çalışmada bazı mesleki eğitim önerilerine de ulaşılmıştır. 2019 Kasım Dönemi Mesleki Çalışma Programı etkinlik temelli bir program olmasına rağmen öğretmenlere bu dönemde mesleki eğitim verilip verilmemesi ile ilgili görüşleri soruldu. Çalışmaya katılan 281 öğretmenin hemen hemen hepsi, mesleki eğitimlerin de eklenmesi gerektiğini belirtti. Bu soruya evet olarak yanıt veren öğretmenlerin 
ihtiyaç duydukları mesleki eğitimler ile ilgili bulgular öğretmenlerin ölçme-değerlendirme, yaratıcı drama, materyal geliştirme, ders programı hazırlama ve bilişim teknolojileri konularında eğitim almak istediklerini göstermiştir. Katılımcıların yaş ve mesleki deneyimlerine bakıldığında, üniversiteden çok yakın zamanda mezun oldukları sonucuna varılabilir. Hemen her üniversitenin eğitim fakültelerinde bu konularda eğitimler verilmesine rağmen öğretmenlerin bu eğitimlere ihtiyaç duymaları üniversite eğitimleri boyunca ya böyle bir eğitim almadıkları ya da aldıkları eğitimin yetersiz olduğu sonucunu göstermektedir.

Öğretmenlerin mesleki eğitimin zamanlaması hakkındaki görüşleri ile ilgili bulgular incelendiğinde, öğretmenlerin mesleki eğitim programının sene başı, ara tatiller ve sene sonunda yapılması taraftarı olduğunu göstermektedir. Mesleki çalışma programlarının sürece yayıldığını gösteren bulgu, bu eğitimin sürece yayılmasını öneren Boydak-Özan vd. (2014) ile İlğan'ın (2013) çalışmalarıyla aynı doğrultudur.

Son olarak, çalışmanın nitel bulguları öğretmenlerin mesleki eğitim programının ara tatilde verilmesi ile ilgili olumlu ve olumsuz görüşlerinin yanında birçok öneride de bulunduğunu göstermiştir. Olumlu görüşlerden başlamak gerekirse, öğretmenler, mesleki çalışmanın ara tatilde yapılmasının daha etkili, daha eğlenceli, dinlendirici, rahatlatıcı ve motivasyon arttırıcı bulmuş, bu sayede enerji depoladıklarını ve bir durum değerlendirmesi yapma firsat1 elde ettiklerini belirtmişlerdir.

Karar vericiler tarafindan getirilen her uygulamada karşılaşılacağı gibi bu uygulama için de bazı olumsuzluklar yaşandığını söylemek mümkündür. Olumsuz görüşlere bakıldığında, öğrencilerin derslerden kopması, öğrencilerin tatilden sonra derslere adapte olmakta zorluk çekmesi ve öğrencilerin uyku problemi yaşamaları gibi tamamen öğrencilerle ilgili olumsuz görüş belirttikleri görülmüştür. Kaya (2020) ve Doğan (2020) da benzer bulgulara ulaşmış ve Doğan (2020) bunlara ek olarak en önemli sorunun birinci sınıfların tatilde okuma-yazmayı unutması olduğu sonucuna varmıştır. Bu sorunu engellemek ya da çözmek için ilkokul birinci sınıfta öğrencisi olan velilere ara tatilde kendi başlarına uygulayabilecekleri bir program verilmesi büyük önem taşımaktadır.

Öğretmenlerin ara tatil mesleki eğitim programı ile ilgili önerileri incelendiğinde, öğretmenlerin, mesleki çalışmalar için daha hafif bir program hazırlanması, zümre bazlı eğitim verilmesi, yapılan eğitim ve etkinliklere farklı illerde katılımın mümkün kılınması, ihtiyaç duyulduğu zamanlarda yapılması, program ve etkinliklerin daha erken duyurulması, etkinliklere öğrenci katılımının sağlanması, öğrencilerle şehir içi ve şehirler arası geziler 
düzenlenmesi, mesleki geziler düzenlenmesi, farklı illerde farklı etkinlikler düzenlenmesi, öğretmenlerin okula gelmemeleri, ara tatil verilirken bölgesel farklılıkların göz önünde bulundurulması, ihtiyaca yönelik eğitimler hazırlanması, eğitimlerin alanında uzman kişilerce verilmesi, ve ara tatilde mesleki çalışma programlarına devam edilmesi gerektiği yönünde görüş belirtmişlerdir. Farklı bölge ve okullarda çalışan öğretmenlerin mesleki gelişim ihtiyaçları arasında farklılıklar olduğu sonucuna varan Akar'ın (2006) çalışması gibi bu araştırmaya katılan öğretmenler de bireysel ihtiyaçların göz önüne alınması gerektiğini önermişlerdir. Mesleki eğitimlerin uzman ve yetkin olmayan kişiler tarafından yürütüldüğü sonucuna varan Boydak-Özan vd. (2014), Gümüş (2006), ve Öztürk ve Sancak'ın (2007) çalışmaları gibi bu çalışma da bu eğitimlerin alanında uzman kişiler tarafından verilmesini önermektedir. Son olarak, Doğan (2020) ve Kaya (2020) tarafından da önerildiği üzere tatile yönelik öğrenci ve öğretmenlere yönelik bir program düzenlenmelidir. Ayrıca, Kaya (2020) ara tatilde öğrencilere yönelik sinema ve tiyatro gibi sanatsal ve kültürel faaliyetlerin azlığına değinmiş ve öğrencilere uygun içerikteki bu tür faaliyetlerin düzenlenmesine önem verilmesi gerektiğini önermiştir. $\mathrm{Bu}$ durum, eğitim ile ilgili yapılan bu değişikliğin sadece eğitimle sınırlı kalmayıp toplumsal hayatı da doğrudan etkilediğini göstermektedir.

Sonuç olarak, radikal bir değişiklikle mesleki çalışma programının ara tatilde verilmesi, eğitim ve öğretimin en önemli unsurlarından biri olan öğretmen grubu tarafindan olumlu karşılandığını söylemek mümkündür. Kaya (2020), ortaokul öğrencilerinin bu uygulamadan oldukça memnun olduklarını ve uygulamanın devam ettirilmesi gerektiği sonucuna varmıştır. Dolayısıyla, karar vericiler tarafindan paydaşların görüşleri alınmadan uygulanan ara tatil uygulamasının, bu bulgular ışığında, doğru bir karar olduğu öne sürülebilir.

İlerideki araştırmalar, eğitim-öğretimin diğer önemli paydaşları olan okul yöneticileri ve veli grubunun bu değişikliği nasıl değerlendirdiğine odaklanabilir. Bu çalışma Ağrı ili merkez ortaokullarında çalışan ortaokul öğretmen grubu ile sınırlıdır, benzer çalışmalar başka bölge, il ve/ya ilçelerde ve diğer kurumlarda (ilkokul ve lise) çalışan öğretmenlere de uygulanarak sonuçlar karşılaştırılabilir.

Araştırmada varılan bulgulardan hareketle aşağıdaki öneriler geliştirilmiştir:

- Öğretmene Vefa temasında olduğu için daha etkinlik ağırlıklı olarak hazırlanan bu programa mesleki eğitimler de eklenmelidir. 
- Mesleki eğitimlere karar verilirken öncelikle öğretmenlerin ihtiyaç duyduğu eğitimler araştırılmalı, bu eğitimlerde öğretmenlere seçme hakk1 tanınmalı, herkese ihtiyaç duyduğu eğitimi alma şansı tanınmalıdır.

- Farklı bölgelerde farklı eğitimler, kurslar veya çalıştaylar vb. sunulabilir ve isteyen öğretmenlerin ihtiyaçları doğrultusunda başka bölge ve/ya şehirlere gidip bu etkinliklere katılmaları sağlanabilir.

- Hazırlanacak eğitimlerin mutlaka alanında uzman kişilerce verilmesi sağlanmalıdır.

- Yapılacak etkinliklere öğrenci katılımı sağlanmalıdır.

- Son olarak ara tatil uygulaması devam ettirilmeli ama yukarıda belirtilen hususlara da dikkat edilmelidir.

\section{Makalenin Bilimdeki Konumu}

Eğitim Bilimleri Bölümü/Öğretmen Eğitimi, Eğitim Programları

\section{Makalenin Bilimdeki Özgünlüğü}

Eğitimin en önemli paydaşları en ufak değişiklikten doğrudan etkilenen öğretmen, öğrenci, veli ve okul yöneticileridir. Beraberinde birçok etki getirmesi muhtemel olan ara tatil uygulaması hakkında paydaşların görüşlerinin incelenmesi önem arz etmektedir. Yukarıda bahsedildiği gibi, alanyazında sadece sınıf öğretmenleri ve öğrenci görüşlerine dayanılarak yapılmış çalışmalar bulunmaktadır. Ara tatilin, ilkokul, ortaokul ve lise seviyelerindeki paydaşlar tarafindan farklı değerlendirilmesi muhtemeldir. $\mathrm{Bu}$ çalışmada ortaokul öğretmenlerinin görüşlerine başvurularak karşılaştırmalar yapılmıştır.

\section{Kaynaklar}

Akar, E. (2006). Farklı türde okullarda çalışan biyoloji öğretmenlerinin mesleki gelişim deneyim ve ihtiyaçları. Hacettepe Üniversitesi Eğitim Fakültesi Dergisi, 30(2006), 174183.

Akdemir, A. S. (2013). Türkiye'de öğretmen yetiştirme programlarının tarihçesi ve sorunları. Turkish Studies - International Periodical For The Languages, Literature and History of Turkish or Turkic, 8(12), 15-28.

Aykaç, N., Kabaran, H., \& Bilgin, H. (2014). Türkiye'de ve bazı Avrupa Birliği ülkelerindeki öğretmen yetiştirme uygulamalarının karşılaştırılmalı olarak incelenmesi (Almanya, Finlandiya, Fransa, İngiltere ve Türkiye Örneği). Turkish Studies - International 
Periodical For The Languages, Literature and History of Turkish or Turkic, 9(3), 279292.

Bartlett, J. E, Kotrlik, J. W., \& Higgins, C. C. (2001). Organizational research: Determining appropriate sample size in survey research. Information Technology, Learning, and Performance Journal, 19(1), 43-50.

Boydak-Özan, M., Şener, G., \& Polat, H. (2014). Sınıf öğretmenlerinin mesleki gelişim eğitimlerine ilişkin genel görüşlerinin belirlenmesi. Uşak Üniversitesi Sosyal Bilimler Dergisi, 7(4), 167-180.

Celep, C. (2008). Sinıf yönetiminde kuram ve uygulama. Ankara: Anı Yayıncılık.

Ceylan, M., \& Özdemir, S. M. (2016). Türkiye ve İngiltere'deki öğretmenlerin sürekli mesleki gelişimine ilişkin görüşlerinin ve katılım durumlarının incelenmesi. Kırıkkale Üniversitesi Sosyal Bilimler Dergisi, 6(1), 399-417.

Cohen, L., Manion, L., \& Morrison, K. (2007). Research methods in education. London and New York: Taylor and Francis Group.

Creswell, J. W. (2009). Research design: Qualitative, quantitative, and mixed methods approaches (3rd Ed.). USA: Sage Publications.

Doğan, A. (2020). Sınıf öğretmenlerinin ara tatillere yönelik görüşleri. O. Köse ve Y. UlutürkSakarya (Ed.), Sosyal bilimlerde yeni araştırmalar-III. Ankara: Berikan Yayıncılık.

Elçiçek, Z. (2016). Öğretmenlerin mesleki gelişimine ilişkin bir model geliştirme çalışmast. (Yayımlanmamış doktora tezi). Gaziantep Üniversitesi, Gaziantep.

Fraenkel, J. R, Hyun, H.H., \& Wallen, N.E. (2012). How to design and evaluate research in education (8th Ed.). New York: McGraw Hill

Gall, M. D., Gall, J. P., \& Borg, W. W. (2003). Educational research: an introduction. USA: Pearson Education Inc.

George, D., \& Mallery, P. (2003). SPSS for Windows step by step: A simple guide and reference. 11.0 update. Boston: Allyn \& Bacon.

Güleç, İ., Çelik, S., \& Demirhan, B . (2012). Yaşam boyu öğrenme nedir? Kavram ve kapsamı üzerine bir değerlendirme. Sakarya University Journal of Education, 2(3), 34-48.

Gültekin, M., Güvey-Aktay, E., \& Gültekin, I. (2018). İlköğretimde mesleki çalışma (seminer) dönemi uygulamalar1. Anadolu Journal of Educational Sciences International, 8(2), 482513. 
Gültekin, M., \& Çubukçu, Z. (2008). İlköğretim öğretmenlerinin hizmet içi eğitime ilişkin görüşleri. Sosyal Bilimler Dergisi, 19, 185-201.

Gümüş, C. (2006). Milli Eğitim Bakanlığına bağlı ilköğretim okullarında çalışan öğretmenlerin zorunlu olarak katıldıkları mesleki eğitim çalışmalarının değerlendirilmesine ilişkin uygulamalı bir araştırma. (Yayımlanmamış yüksek lisans tezi). Niğde Üniversitesi, Niğde.

Güneş, F. (2016). Mesleki gelişim yaklaşımları ve öğretmen yetiştirme. Adıyaman Üniversitesi Sosyal Bilimler Enstitüsü Dergisi, 8(24), 1006-1040.

İlğan, A. (2013). Öğretmenler için etkili mesleki gelişim faaliyetleri. Uşak Üniversitesi Sosyal Bilimler Dergisi, Özel Sayı, 41-56.

Kaya, S. (2020). Türk Eğitim Sistemi’nde yeni dönem: Ara tatil. Turkish Studies -Educational Sciences, 15(2), 1049-1059. https://dx.doi.org/10.29228/TurkishStudies.40272

Kayabaş, Y. (2008). Öğretmenlerin hizmet içi eğitimde yetiştirilmesinin önemi ve esasları, Türkiye Sosyal Araştırmalar Dergisi, 12(2), 9-32.

Merriam, S. B. (2009). Qualitative research: A guide to design and implementation, revised and expanded from qualitative research and case study applications in education. San Francisco: Wiley.

Miles, B. M., \& Huberman, A. M. (1994). Qualitative data analysis: An expanded sourcebook. (2nd Ed.). USA: Sage.

Öztürk, M., \& Sancak, S. (2007). Hizmet içi eğitim uygulamalarının çalışma hayatına etkileri. Journal of Yasar University, 2(7), 761-794.

Resmi Gazete (2019a). 30827 sayılı Millî Eğitim Bakanlığı Okul Öncesi Eğitim ve İlköğretim Kurumları Yönetmeliğinde Değişiklik yapılmasına Dair Yönetmelik. (Çevrimiçi: https://www.resmigazete.gov.tr/eskiler/2019/07/20190710-6.htm), Erişim tarihi: 10 Temmuz 2019.

Resmi Gazete (2019c). 30919 sayılı Millî Eğitim Bakanlığı Öğretmenler Günü Kutlama Yönetmeliği.(Çevrimiçi:https://www.resmigazete.gov.tr/eskiler/2019/10/201910154.htm), Erişim tarihi: 15 Ekim 2019.

Resmi Gazete (2019b). 30829 sayılı Millî Eğitim Bakanlığı Ortaöğretim Kurumları Yönetmeliğinde Değişiklik yapılmasına Dair Yönetmelik. (Çevrimiçi: https://www.resmigazete.gov.tr/eskiler/2019/07/20190712-10.htm), Erişim tarihi: 12 Temmuz 2019. 
Milli Eğitim Bakanlı̆̆ı. (2019). Öğretmenlerin 2019 Kasım Dönemi Mesleki Çalışma Program1.(Çevrimiçi:http://meb.gov.tr/meb_iys_dosyalar/2019_11/18123523_18193654 _Mesleki_CalYYma.pdf), Erişim tarihi: 20 Ekim 2019.

Seferoğlu, S. S. (2004). Öğretmen yeterlikleri ve mesleki gelişim. Bilim ve Aklın Aydınlığında Ĕ̈itim, 58, 40-45.

Tonbul, Y. (2004). İlköğretim okullarındaki mesleki çalışma uygulamalarının etkililiği ile ilgili görüşler. Eğitimde Yeni Yönelimler Sempozyumu. Tevfik Fikret Okulları, Ankara.

Üstüner, M. (2004). Geçmişten günümüze Türk Eğitim Sisteminde öğretmen yetiştirme ve günümüz sorunlar1. Inönü Üniversitesi Eğitim Fakültesi Dergisi, 5, [Çevrimiçi: https://www.pegem.net/Akademi/3-8232-Gecmisten-Gunumuze-Turk-Egitim-

Sisteminde Ogretmen-Yetistirme-ve-Gunumuz-Sorunlari.aspx], Erişim tarihi: 9 Kasım 2019.

\section{Extended Summary}

\section{Introduction}

Teachers who will shape the future of the society are expected to receive an effective education and keep up with the changing times and conditions by constantly improving themselves so that they can provide a quality education. This situation requires the teacher training process to be continuous. Teacher training consists of activities carried out to prepare prospective teachers for the teaching profession within a certain period of time (Aykaç, Kabaran \& Bilgin, 2014). In Turkey, this process consists of pre-service training, appointment as public personnel and in-service training (Akdemir, 2013). Postgraduate education can also be added to these trainings (Güneş, 2016), because postgraduate education is an important education that will contribute to their professional development.

Teachers' acquisition of necessary knowledge and skills throughout their professional life and their development are met through in-service training programs (Gültekin, GüveyAktay \& Gültekin, 2018). In this sense, professional development can be considered as a reflection of lifelong learning (Elçiçek, 2016), because "lifelong education is a general arrangement that aims to restructure the existing system and develop all the potential related to education outside the formal education system” (Güleç, Çelik \& Demirhan, 2012, p. 35).

As known, until the 2018-2019 academic year, teachers were given professional training under the name of the seminars which were given at the beginning and at the end of the academic year. However, when the literature on this issue indicates that these training are not 
very effective. Studies show that teachers see professional development seminars as a formality (Ceylan \& Özdemir, 2016; Tonbul, 2004) and the results of the study reports are not used, namely, they are ignored (Tonbul, 2004); these studies are not carried out by experts and competent staff (Boydak-Özan, Şener, \& Polat, 2014; Gümüş, 2006; Öztürk \& Sancak, 2007); the activities are necessary and useful, but the time allocated for these studies is insufficient (Gültekin \& Çubukçu, 2008; Gümüş, 2006); the time allocated for the activities is not of good quality (Gümüş, 2006); there are differences between the professional development needs of teachers working in different regions and schools (Akar, 2006) and that they are not applied in congruent with their intended purpose (Boydak-Özan et al., 2014).

In line with the objectives of the Ministry of National Education's [MoNE] 2023 Education Vision, a new professional development program based on activity-based practice has been prepared to support the individual and professional development of the teachers (MoNE, 2019). With the changes made in the recent regulations, it was decided to hold professional training programs not only at the beginning and end of the academic year, but also during two mid-term breaks. In this sense, one of the mid-term breaks was decided to be conducted in November, while the second one was decided to be applied in April. This newly prepared program has been put into practice starting in November of the 2019-2020 academic year. Thus, the teachers will be provided with professional development programs four times within the process. As known, each of the seminars held at the beginning and the end of the year lasted two weeks. With this change, these seminars were shortened by one week, and the two-week professional training programs were to be held in one-week periods during the midterm breaks in November and April.

When the literature is examined, it is seen that there are two studies conducted on this recent change. The first of these studies was conducted by Doğan (2020) in a qualitative study in order to obtain the opinions of classroom teachers about mid-term breaks. As a result of the study, he reached some positive and negative findings about the mid-term breaks based on the opinions of the teachers.

Another study was conducted by Kaya (2020) to examine how middle school students viewed the mid-term break practice. As a result of the study, it was found that the students had a productive break, they were generally satisfied with the break and they recommended that the mid-term breaks should be continued. 


\section{Purpose of the Study}

The most important stakeholders of education are teachers, students, parents and school administrators who are directly influenced by any slightest change. To this connection, it is important to examine the views of stakeholders about this practice, which is likely to have many impacts. As mentioned above, studies have been conducted based on the opinions of classroom teachers and students regarding the mid-term break. It is likely that the break will be perceived and viewed differently by other stakeholders working in primary, secondary and high schools. The aim of this study was to examine the opinions of middle school teachers about the midterm break practice and the following research questions were formulated to be answered:

1. What are the teachers' opinions about the activities of the professional training program held in November 2019?

2. What are the training that teachers want to be added to the professional training program?

3. What are the teachers' views on the timing of the professional training programs?

\section{Method}

In this study, a mixed-methods research model was used, benefiting from the strengths of both quantitative and qualitative methodologies (Cresswell, 2009) by making use of data triangulation, because both methodologies provide a better understanding of the researched phenomenon (Fraenkel \& Wallen, 2012). In this study, the concurrent embedded strategy proposed by Creswell (2009) was used. The main feature of this strategy is its use of a primary method to lead research as well as a secondary data that provides a supporting role.

The population of the study consisted of 1014 middle school teachers working in 42 schools located in the city center of Ağrı. The cluster sampling method, one of the random sampling methods, was used in the selection of the sample. With this method, numbers were given to 42 schools and all teachers working in schools selected by lot were included in the sample of this study. At the end, 14 schools were selected as a result of the random selection and questionnaires were distributed to 302 teachers working in these schools. 281 of these teachers completed and handed the questionnaire. Therefore, the sample of this study consists of 281 teachers.

A semi-structured questionnaire was developed by the researcher to find answers for the research questions. At the end of the validity and reliability processes, the questionnaire had a part on demographic characteristics of the participants and a second part, which included three 
sub-sections, composed of 25 items. In addition, an open-ended question was added to the questionnaire. The quantitative data were analyzed with mean, frequency and percentages, while the qualitative data obtained from the open-ended question were analyzed through content analysis.

\section{Findings and Discussion}

The findings with respect to teachers' opinions about the activities, showed that the activities were implemented as planned, they were interesting, efficient, met expectations, and contrary to the study conducted by Boydak-Özan et al. (2014), this program was carried out in congruent with its intended purpose. Based on these findings, it can be concluded that the activity selection was successful. In addition, contrary to the studies that concluded that teachers saw seminars as a formality (Ceylan \& Özdemir, 2016; Tonbul, 2004), this research showed that the program was implemented as planned.

Further findings revealed that the activities enabled teachers to socialize in their working environment, develop a positive attitude towards the institutions they work in, develop their sense of belonging to the institution they work in, enable them to get to know their colleagues better, get to know the region where they worked, learn the historical, natural and cultural characteristics of the region they worked in, and ensure their refreshment. Based on these findings of the teachers' opinions about the activities offered to them within the framework of the professional training program, it can be concluded that the teachers' satisfaction levels were quite high.

The findings regarding the teachers' opinions about the timing of the professional training program indicated that teachers favored the timing. Finally, the qualitative findings of the study showed that the teachers made many suggestions besides their positive and negative opinions about the timing. To start with the positive opinions, the teachers stated that doing the professional training work during the break was more effective, more enjoyable, relaxing, and motivating, thus they stored energy. The negative opinions revealed that the students had difficulty in adapting to the lessons after the break, and they had sleep problems.

As a result, it can be argued that the practice applied by decision makers without taking the opinions of the stakeholders is a correct decision in light of these findings. Further research may focus on how school administrators and parents, who are other important stakeholders of education, see this change. In addition, this study is limited to the middle school teachers working in the middle schools located in Ağrı city center, so similar studies can be conducted 
to teachers working in other regions, provinces and/or districts and other institutions (primary and high schools) and the results can be compared. 